\title{
Atrioventricular Conduction ECG Assessment
}

National Cancer Institute

\section{Source}

National Cancer Institute. Atrioventricular Conduction ECG Assessment. NCI Thesaurus. Code C111131.

An electrocardiographic assessment of the transmission of electrical impulses between the atria and ventricles. 